\title{
MULTI-SENSOR DOCUMENTATION OF METRIC AND QUALITATIVE INFORMATION OF HISTORIC STONE STRUCTURES
}

\author{
E. Adamopoulos a, ${ }^{\text {a }}$, E. Tsilimantou a , V. Keramidas a , M. Apostolopoulou a, M. Karoglou a, S. Tapinaki b, \\ C. Ioannidis ${ }^{\mathrm{b}}$, A. Georgopoulos ${ }^{\mathrm{b}}$, A. Moropoulou ${ }^{\mathrm{a}}$ Polytexneiou 9, 15780, Athens, Greece, E-mail: eadamop@outlook.com, eltsilim@mail.ntua.gr, bkeramidas@hotmail.gr, mairi_apostol@hotmail.com, margo@central.ntua.gr, amoropul@central.ntua.gr
${ }^{\mathrm{b}}$ Laboratory of Photogrammetry, School of Rural \& Surveying Engineering, National Technical University of Athens, Iroon \\ ${ }^{a}$ Laboratory of Materials Science \& Engineering, School of Chemical Engineering, National Technical University of Athens, Iroon \\ Polytexneiou 9, 15780, Athens, Greece, E-mail: sevi@survey.ntua.gr, cioannid@survey.ntua.gr, drag@central.ntua.gr
}

KEY WORDS: Documentation, Built Heritage, Materials, Decay, Geographic Information System

\begin{abstract}
This paper focuses on the integration of multi-sensor techniques regarding the acquisition, processing, visualisation and management of data regarding historic stone structures. The interdisciplinary methodology that is carried out here comprises of two parts. In the first part, the acquisition of qualitative and quantitative data concerning the geometry, the materials and the degradation of the tangible heritage asset each time, is discussed. The second part, refers to the analysis, management and visualization of the interrelated data by using spatial information technologies. Through the paradigm of the surveying of the ancient temple of Pythian Apollo at Acropolis of Rhodes, Rhodes Island, Greece, it is aimed to highlight the issues deriving from the separate application of documentation procedures and how the fusion of these methods can contribute effectively to ensure the completeness of the measurements for complex structures. The surveying results are further processed to be compatible and integrated with GIS. Also, the geometric documentation derivatives are combined with environmental data and the results of the application of non-destructive testing and evaluation techniques in situ and analytical techniques in lab after sampling. GIS operations are utilized to document the building materials but also to model and to analyse the decay extent and patterns. Detailed surface measurements and geo-processing analysis are executed. This integrated approach, helps the assessment of past interventions on the monument, identify main causes of damage and decay, and finally assist the decision making on the most compatible materials and techniques for protection and restoration works.
\end{abstract}

\section{INTRODUCTION}

The necessity of the recording of historical stone structures and in general of the built heritage, has been highlighted multiple times by international agreements and directives, such as in the Venice Charter (ICOMOS, 1964). Also, more recently, the recording of historical, architectural, geometric, geographical, structural, physicochemical and environmental data has been pointed out as an integral part of the integrated documentation required for the decision making on preservation and restoration interventions for the architectural heritage assets, as mentioned in the works of Moropoulou et al. (2003) and Letellier et al. (2015).

Within the framework formed by contemporary theoretical trends for the protection of architectural heritage (Pereira, 2007), practical needs arising from the necessity for integrated and sustainable management (Nasser, 2003) and the experience acquired from decades of incompatible interventions, derives the need for integrated approaches in conservation. The faults of the past regarding unilateral, fragmentary approaches, about state diagnoses and conservation interventions on cultural heritage monuments, have led to the realization of the need for holistic, interdisciplinary, and continuous documentation, which enables accurate decision-making concerning built heritage protection. As discussed in Kioussi et al. (2012), the documentation of a cultural heritage asset should be detailed, multi-scalar and cover a wide range of information, that will assist the methods followed for the inspection, diagnosis, intervention study, pilot and final intervention works assessment and monitoring.

The interdisciplinary documentation of tangible heritage refers to archaeological, architectural, geodetic and structural surveys, but also, investigation procedures concerning the environment, the building materials and their decay, the previous interventions and the current state of the structure's conservation (Moropoulou et al., 2005). Documentation methods exploit state-of-the-art and traditional methods/ techniques to acquire, visualize and manage metric and qualitative data that depict the current state of the monument and the factors (endogenous and exogenous) that affect it.

The results of the documentation can be integrated in an ITC environment (Salonia \& Negri, 2003; Tsilimantou, 2018). By analyzing them, it is possible to assess previous interventions, identify the extent, causes and mechanisms of weathering and damage and help the selection of compatible materials and techniques for protection and restoration works (Delegou et al., 2011; Delegou et al., 2012). A key feature of the interrelated interdisciplinary data is the spatial correlation which enables geoprocessing techniques.

The present work concentrates on multi-sensor documentation methods, their interrelation and contribution and therefore on their integration for the assessment of the current state of cultural heritage assets through geographical information systems (GIS). Metric 3D surveying and non-destructive testing and evaluation (NDT \& E) techniques are explored as tools which can support the multidisciplinary documentation of interrelated metric and qualitative data for the diagnosis of decay patterns and causes. The abovementioned methodology was tested on the case of the Temple of Pythian Apollo of Rhodes in an attempt to provide a powerful tool that can assist the decision making on compatible materials and techniques for protection and restoration works.

The proposed workflow for the acquisition, processing, visualization, management and analysis of data, includes all relevant standards and can serve as a prototype methodological approach for a variety of cultural heritage assets. It can contribute to the dissemination among the scientific community and citizens and can be used for avoiding similar incompatible interventions, raising awareness among people and scientists to microclimate pressures and threats. 


\section{WORKFLOW FOR THE AQCUISITION AND FUSION OF INTERRELATED DATA}

A workflow for the integrated documentation of historic stone structures incorporates many levels of data recording and fusing. The main categories of information that represent the shape and the current state of a monument are historical, archaeological, geometric, structural, environmental or refer to physicochemical characteristics of the materials (mineralogical, microstructural, hygrothermic and decay patterns information). The basic steps of the multi-disciplinary procedure are presented below.

The historical-archaeological documentation aims to a complete and in-depth understanding of the structure and its history, through thorough bibliographic research and collection of photographs, sketches, plans, historical texts and other printed documents. Prefers to collect information about the location, construction, history, significance, values, historical background of the structure and in general the documentation of the present state, but also to support the study with evidence; not just in terms of the historic structural phases, but also regarding existing deformations and anomalies, the analysis of deterioration and possible previous incompatible interventions, in order to assess damages and static integrity (Genovese, 2005).

The architectural documentation supported by the results of the archaeological research aims at the extensive expansion of the knowledge concerning the structural phases and additionally, attempts to critique the mechanisms and other factors that cause deformations and deviations to the monument and investigates the original shape of the structure and its components.

The geometric documentation of historic structures provides methods and techniques that produce figurative products (vector drawings, images, three-dimensional reconstructions) in various scales, which usually have metric properties, especially when referring to an orthographic system. Thus, geometric recording can produce two-dimensional drawings, which in fact represent projections of the monument on vertical and horizontal levels (Georgopoulos, 2016). Contemporary techniques include: measurements with geodetic total stations and GNSS receivers to represent the shape/size of medium size objects, but also to support other surveying techniques; triangulation, time-of-flight and phase difference scanners to collect large point clouds in a short time for the creation of accurate 3D models of various dimensions and complexity (Ioannidis and Georgopoulos, 2007); digital close-range photogrammetry, as a more economic and efficient method to acquire measurements and 3D models with or without texture (Yilmaz et al., 2007) or UAV large scale mapping (Georgopoulos et al., 2016); combinations of the above mentioned techniques (Guarnieri et al., 2006) or coupling with other NDT, such as GPR (Agrafiotis et al., 2017), thermal or multispectral data for various applications. Geometric documentation products supplement and are supplemented by architectural drawings. They form a geographic background, for the absolute reference and the relative spatial correlation of all the other collected quantitative and qualitative data of the integrated documentation. Additionally, they offer a base for the digitization required to produce thematic maps of materials, decay patterns, previous interventions and other characteristics of the structure.

The structural documentation focuses on the investigation of the structural system, the dimensions and strengths of the bearers of loads, information that can be used in stress simulations with the help of computational tools. The stages of this survey generally include (Binda, 2005): recognition of the bearing elements and their geometry, of the cracks and the mechanical damage; an initial assessment of the state of the structure and the possibly necessary repairs or reinforcements (combined with additional or specific measurements); the identification of appropriate actions to monitor deformations and movements. NDT \& E can be of great importance for the structural documentation. More specifically, UltraSonic tests (US) for the weathering determination of the materials (cracks, discontinuities etc.) and Ground Penetrating Radar (GPR) for the determination of the materials thickness in a structure and the location of their interfaces, Schmidt Hammer Test (SHT) for the calculation of the materials compressive strengths (Moropoulou et al., 2005a). Regarding the correlation with other types of documentation, historic documentation is vital for the determination of the system of bearers by archival research; geometric documentation is important since it provides precise dimensions of the structure, contributing both in the identification of the geometry of bearers and in the calculation of loads. The structural documentation contributes to the supplementation of architectural drawings with information for the materials, the construction techniques, the loads and the mechanical damages.

The diagnostic survey follows the rest of the interdisciplinary documentation; it starts with visual observations of the structure and the relation to the surrounding environment. The diagnosis includes characterizations of historic materials and their origin, evaluation of the past interventions and environmental impact assessment. It concerns the monitoring of environmental factors, NDT \& E in-situ and in lab analysis of the mechanisms and products of decay associated with endogenous and exogenous factors in the scale of the monument (Moropoulou, et al. 2013). More specifically, the first step of the diagnosis is to gather the existing archaeological documentation for historical materials, phases and previous interventions, as well as information about the environmental conditions such as temperature and humidity, winds, rain precipitation, frost, solar radiation, concentration of pollutants and other particles. Continuously, rough conclusions are extracted. In the case that a diagnostic study of the materials is necessary, some representative areas of investigation are selected in the structure to apply NDT \& E techniques and sampling. The NDT \& E techniques applied on a case-by-case basis are (IAEA, 2002; Moropoulou et al., 1997; Moropoulou et al., 2013): Fiber Optic Microscopy (FOM), to investigate surface morphology, to identify differences in texture and composition on surfaces and to classify materials and decay; Digital Image Processing (DIP) to categorize features and patterns on architectural surfaces which facilitates building materials and decay mapping; InfraRed Thermography (IRT) for recording radiation from surfaces, which may indicate areas of increased or reduced emissions, revealing the presence of heterogeneities; GPR; US; SHT; Thermo-Hygrometry and Colorimetry. The complementary use of various instrumental lab methods after sampling, completes the knowledge of historical materials and decay, on mineralogical and physicochemical characteristics. The most commonly used techniques are (Middendorf et al., 2005a; Middendorf et al., 2005b): Optical Polarization Microscopy (OM), for petrological-mineral characterization, as well as microscopic observations of different mineral phases; $\mathrm{X}$ Ray Fluorescence spectroscopy (XRF) for elemental and chemical analysis; X-Ray Diffraction (XRD) to identify crystalline phases; Fourier Transform Infrared Spectroscopy (FTIR) to collect information on basic chemical characteristics and the presence of salts; Scanning Electron Microscopy (SEM) - X-Ray Energy Dispersion Microscopic Analysis (EDX-MA) for microscopic observation of texture and microstructure and for elemental semi-quantitative analysis; Thermogravimetry (TG) - Differential Thermal Analysis (DTA) - Differential Scanning Calorimetry (DSC) to quantify some of the compounds revealed by XRD analysis and determine the nature of the stones through an analytical process; Water Absorption, to estimate the hygrometric behavior; Mercury Inducing Porosimetry (MIP) to estimate microstructural characteristics. 
The production of a historical GIS includes the design of the necessary background (graphical rendering of the location and shape of the spatial entities describing materials and decay), the creation of topologies and the interconnection of the entities with additional data located in a database. These data are all the results of the integrated documentation and include numerical and descriptive features, images, drawings, reports, diagrams that are integrated in the platform (Moropoulou et al., 2005b). Its value lies in the fact that, barring meeting the needs of thematic mapping, accessing databases and conducting spatial analysis, it can also answer queries referring to: relative and absolute position, various features and complex questions (combining logical and boolean operators).

\section{CASE STUDY}

\subsection{Historical Documentation Data}

The Acropolis of Rhodes lies at the western and highest part of the city of Rhodes, only a short distance from the sea. It was a monumental area consisting of sanctuaries, temples, public buildings and underground worship places, built on different levels, on landscaped platforms which were retained by strong walls. The spirit of Hellenistic architecture at the Acropolis of Rhodes was perfectly expressed by the combination of natural beauty with the craftsmen's interventions. The monuments of the Acropolis date back to the Hellenistic and Late Hellenistic times $\left(3^{\text {rd }}-2^{\text {nd }}\right.$ cent. B.C. $)$

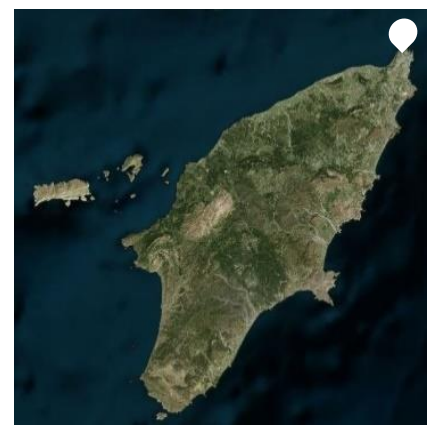

Figure 1: Location of the acropolis of Rhodes on the map of Rhodes Island

The Temple of Pythian Apollo is located in the south of the hill at the west part of the Acropolis. It was of Doric order, peripteral, with dimensions of approximately $20.05 \times 37.70 \mathrm{~m}$, made of local porous stone, with 6 columns at the short side, 11 at the long side and orientated from east to west. The excavations at the Acropolis were carried out by the Italian School of Archaeology during the Italian occupation of the island (1912-1945). During that period extensive reconstructions were conducted, according to the theoretical and practical approaches of the era. Thus, part of the northeast side of the temple was reconstructed with the use of the original stones and contemporary materials (concrete and cement plasters), resulting in a mixed structure. From 1946 onwards, the Greek Archaeological Service proceeded to restore the temple of Pythian Apollo, which suffered great damage from the bombings of the Second World War and the weight of the guns that had been installed there. During the 60's and 70's, restoration works were carried out on the western foundation. In 1996 anastylosis works begun at the same and other nearby temples. The temple in its current form includes the stereobate, the reconstructed elevations to the north and east and four restored columns with a fragment of the entablature and the pediment at the northeast.

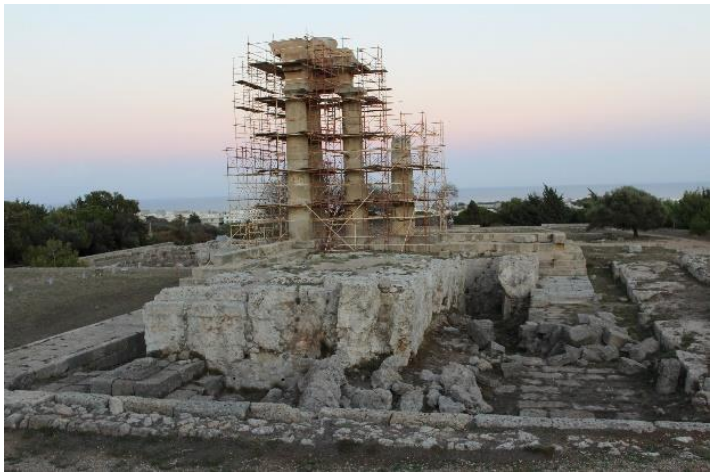

Figure 2: The Temple of Pythian Apollo under scaffolds

\subsection{Architectural Documentation Data}

The drawings which were made available in order to facilitate the interdisciplinary study, were those included in the Ph.D. of the archaeologist Dr. Elisa Fain in her doctoral dissertation: «Comportamento e durabilità delle "strutture miste" in area archeologica. Il Tempio di Apollo Pizio all' Acropoli di Rodi» (Fain, 2015). These plans helped in many cases the interpretation of the 3D data and the comprehension of architectural lines, but also assisted to a first approach in identifying the materials and understanding the causes of mechanical damage.

\subsection{Geometric Documentation}

For the proper geometric documentation of the temple, 2D and 3D products had to be developed which should compose the complete geometry of the monument. These would include:

- a three-dimensional model

- a topographic plan, four façade drawings, one horizontal and two vertical intersections (scale 1:50)

- a high quality textured model, orthoimages of the facades and more detailed drawings (scale 1:25) for the part of the monument (south column) where the pilot applications for the integration of multidisciplinary data would take place

The geometric recording in large scale $(<1: 100)$ presented many difficulties, since a high level of detail was required. Moreover, the data acquisition was held while restoration works were already in progress, meaning that additional effort was required to be quick, precise and to facilitate the executed works. The remains of the temple were surrounded by scaffolds at close distance or even 'in touch' with the monument, resulting in concealments. Also, the architectural lines, surfaces and details were severely degraded or covered by cement mortars and plasters of previous restoration interventions and therefore were difficult to interpret and document. The abovementioned raised issues had to be tackled to ensure the measurements' and visualizations' completion. For this reason, a combination of topographic, photogrammetric and terrestrial laser scanning techniques was utilized for the geometric documentation. The measurements were used to validate the accuracy of the products in cases of excessive information and to supplement the collected data where occlusion occurred.

The field measurements where conducted with a TOPCON 3003 total station with $10 \mathrm{cc}$ and $\pm 3 \mathrm{~mm} \pm 2 \mathrm{ppm}$ accuracy an Altus NR2 GNSS receiver; the scanning was performed with a Leica ScanStation 2 with $12 \mathrm{cc}$ and $\pm 4 \mathrm{~mm}$ accuracy; the digital images were taken by a Canon EOS-1DS Mark III 21MP DSLR $(6.4 \mu \mathrm{m}$ pixel size) with a Canon EF 16 - 35mm lens.

For the field measurements, a geodetic network was established. It consisted of four stations and was measured ensuring the required precision was met. Points measured with the use of total 
station (more than 1,400) included: sampling points of the diagnostic study, pre-signed control points, laser scanner targets, vertical/ horizontal sections and detail points on the entablature and pediment. Measurements were organized in a way that drawing procedures were made faster and errors were avoided. The scans were conducted with a point cloud density of approximately $3-4 \mathrm{~mm}$, with sufficient overlap. The techniques used to align and georeference the individual TLS scans were target-to-target and target-to-total station registration (Van Genechten, 2008). The point cloud was imported in Geomagic Studio to remove unnecessary noise caused by natural or anthropogenic objects -mainly of the scaffolding and the metal mesh surrounding the monument.

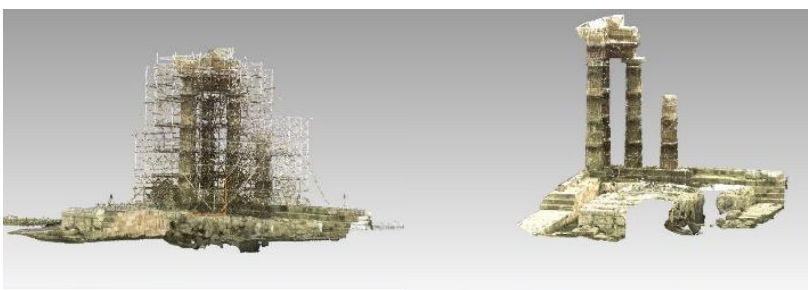

Figure 3: Point cloud of TLS before (left) and after (right) the removal of noise; West façade

After the noise was removed, an attempt was made to create a three-dimensional surface for the whole monument. The density of the information and the concealment problems created by the scaffolding in combination with the scanning angles and the complex morphology of the object, did not allow the complete modeling of the monument, the effort of including patches of photogrammetrically produced models and therefore it was decided to produce only $2 \mathrm{D}$ derivatives. The drawings were created by extracting thin sections of the 3D point cloud and connecting the points, by drawing directly in 3D (Autodesk Recap) and by filling in with photogrammetrically produced sections, points measured individually and details subtracted from architectural plans.

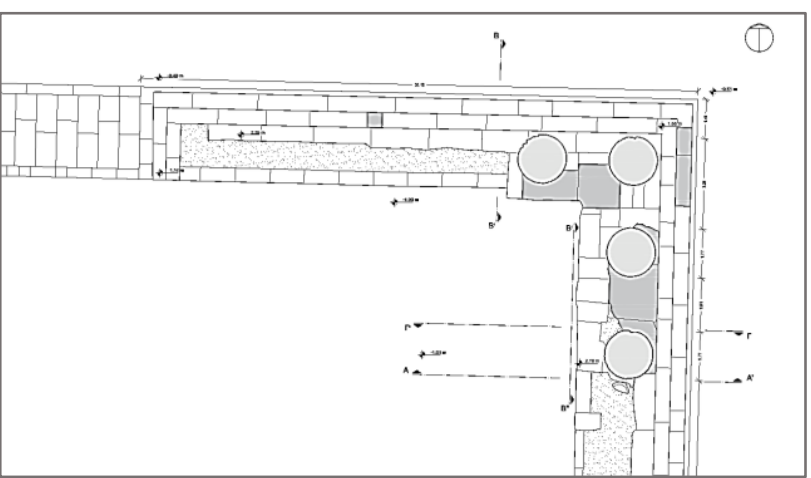

Figure 4: Excerpt of horizontal section drawing

For the detailed documentation of the south restored column a standard automatic photogrammetric procedure was followed, as in Calisi (2016), De Reu at al. (2013) and Pierrot-Deseilligny et al. (2011). The column dimensions were: $7.43 \mathrm{~m}$ in height, 1.80 $\mathrm{m}$ in diameter at the base and $1.50 \mathrm{~m}$ in diameter at the upper part. The capital was absent. The many surface anomalies due to the significant loss of materials resulted to a very rough surface. These features constituted a complex and voluminous object to be recorded, but the detailed documentation was a prerequisite for the thorough mapping of the materials and decay at a following stage of the application.

The planning of image acquisition depends on the characteristics of the object, the processing software and its requirements. For

the creation of the photorealistic 3D model, the SfM (Structure from Motion) technique was applied through the Agisoft PhotoScan Professional software). Due to the available fully automated methodology that contemporary commercial software follows, the photo acquisition planning is of essential importance in order to avoid unsuccessful results and to achieve the required precisions (Nocerino et al., 2014). Also, the general guidelines of CIPA (UNESCO, 1981) and more recent bibliography on the specifications of photogrammetric products for the recording of heritage, and notably Campos et al. (2015), were considered. Image acquisition was conducted following the above mentioned guidelines and with high density in order to acquire all the necessary information without any deficiencies. In particular, the images were taken from a close range, in three overlapping zones (per floor of the scaffolding), perpendicular to the column, about half a step away from each other. In addition, many images were taken serving various purposes, and were mainly:

- to fully capture the detail of the two upper drums, a result of intense alveolization that has led to a perforated surface

- to connect the images between each zone - oblique images (large Phi angles) to the upper and/ or the lower floor

- $\quad$ to improve the geometry of the dataset - randomly oriented images that formed between them at least stereopairs

- $\quad$ to model the top of the column forming a cavity because of the concrete filling - more distant images from the third floor of the scaffolding

- to depict the detail wherever there was a great loss of material and the shape deviated significantly from the normal, closer and denser shots with a larger focal length

In total 640 images where taken. The shots were conducted with a focal length of 16-34 mm (wide angle) focal length lens. Most images were taken with a fixed focal length of $16 \mathrm{~mm}$, from a distance of 1-1.5 $\mathrm{m}$ for the side surfaces and about 3-3.5 $\mathrm{m}$ for the top of the column. The pixel was $6.4 \mu \mathrm{m}$, so the GSD was $0.4-0.6 \mathrm{~mm}$ for the side surfaces and 1.2-1.4 mm for the top. The detail images were taken with a fixed focal length of $34 \mathrm{~mm}$ from up to $0.5 \mathrm{~m}$, i.e. the GSD for that particular set of images was < $0.2 \mathrm{~mm}$. In this application where the final precision of the orthoimages corresponded to the 1:25 scale, the GSD had to be $<2.1 \mathrm{~mm}$, (applied to all distances and focal length combinations). For the georeferencing and the scaling of the 3D model, 27 pre-signed points were placed, suitably scattered an in a way to be visible from at least one geodetic network station. The steps of the reconstruction are presented with Figures $5-8$.

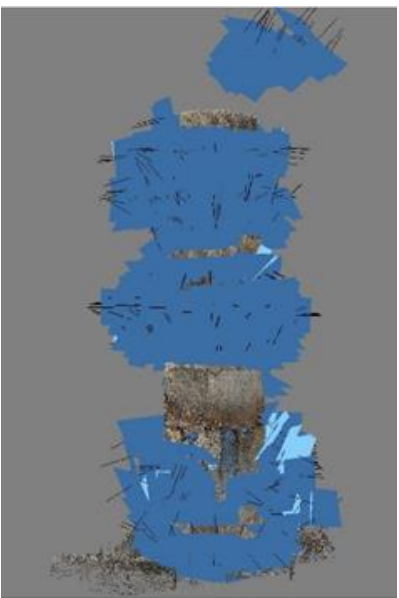

Figure 5: Camera positions estimation and sparse point cloud generation

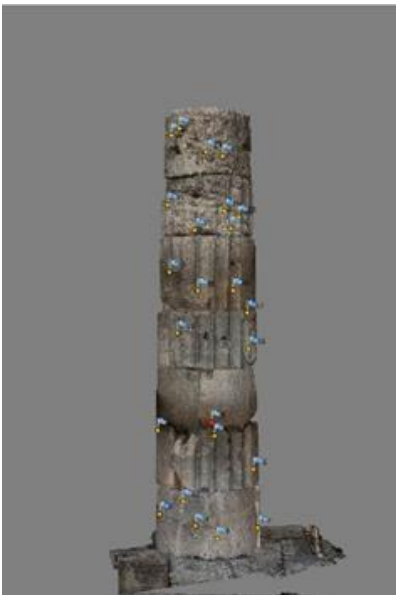

Figure 6: Dense point cloud generation with predefined points for georeferencing and scaling 


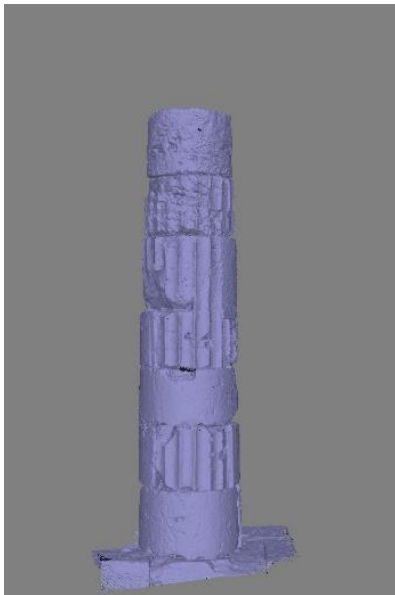

Figure 7: Mesh (surface model) generation

It should be mentioned that initially the dataset of images was divided into four parts, one for each zone of photo shooting and one for the upper part. The matches and point clouds were then calculated individually to reduce processing time. Yet after the merge of the four parts, it occurred that the geometry could not be retrieved properly, because between the lowest and the middle zone a deformation occurred and the upper part could not be connected at all with the rest of the point cloud, despite the carefully selected and marked common control points. After successive approaches, the only safe solution that emerged to represent correctly the geometry of the column, was to divide the dataset into two parts with commonly use of the second zone for both upper and lower part. Only a small common area chosen for the coupling of the two point clouds. Subsequently, after the creation of a single mesh, duplicate surfaces in the common part were deleted.

The errors on the photogrammetrically produced 3D model were marginally acceptable for the pre-decided scale. The pixel size of the orthophotos was $2 \mathrm{~mm}$, acceptable considering the final error, and also necessary for the identification of the boundaries of the materials and the decay products.

\subsection{Structural Documentation}

The structural documentation was conducted in successive steps. At first an identification of the bearing and non-bearing elements and their geometry was attempted, taking into consideration the existing knowledge for the construction of temples of the same order and chronic period and, previous architectural and photographical documentation. Secondly cracks and areas with significant loss of material were recorded. A supplementation of architectural and surveying drawings followed, with information regarding the materials, the construction techniques, the loads and the mechanical damages. An initial assessment of the current state and the, possibly, necessary repairs or reinforcement operations was made, in combination with the NDT \& E for the mechanical characteristics (hammer test). These measurements where conducted on each side and each drum of the south column with $10 \mathrm{~cm}$ intervals. The results of the structural documentation were combined with those of the geometric recording to produce 2D drawings that depicted the geometry of the bearers, in order to facilitate Discrete Element Modelling and analysis.

Thus, these models that contained detailed dimensions and references to the performance, could be used in combination with computer aided tools, to assess the stability of the monument and the response to different seismic events.

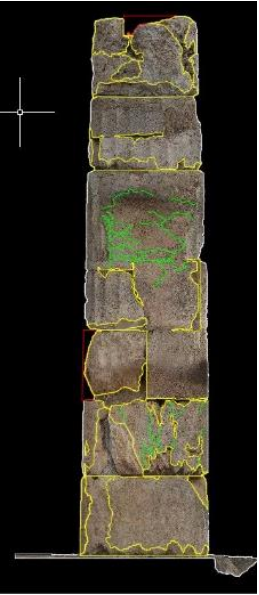

Figure 9: Cracks and loss of materials recording

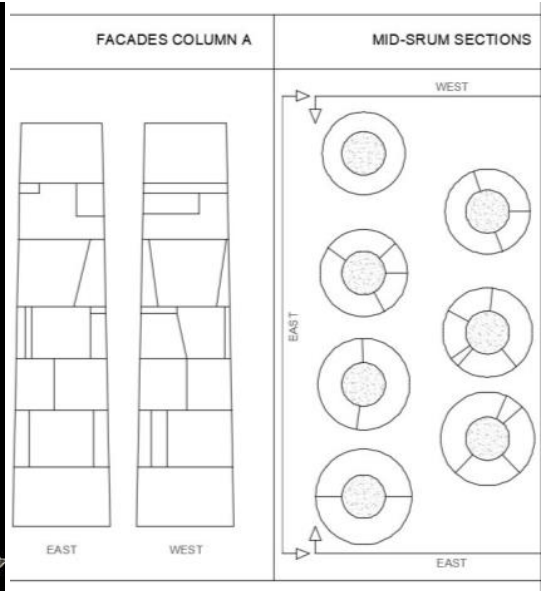
mid-drum sections; plans for assisting FEM modelling
Figure 10: Faces of the south column and

The problems concerning this type of documentation, pertained mainly to the inability to produce true $3 \mathrm{D}$ information about the structural characteristics. The conclusions about the system of loads and bearers derived from surface observations and measurements. Despite the fact that the use of techniques such as sonic tomography or ultrasound testing facilitate the collection of data regarding the "depth" of the materials, they could not be used due to the texture and geometry of the column.

\subsection{Environmental Documentation}

For this type of documentation, two types of data were collected, climatic and microclimatic data. The first acquisition consisted of the research for meteorological data acquired by the nearest meteorological station and the National Meteorological Agency of Greece, namely: temperature, humidity, wind speed, wind direction, atmospheric pressure, rain precipitation, solar exposure and solar radiation. For example, the mean temperature varies from $14.2{ }^{\circ} \mathrm{C}$ to $27{ }^{\circ} \mathrm{C}$ (winter mean $=14.4{ }^{\circ} \mathrm{C}$, spring mean $=14.2{ }^{\circ} \mathrm{C}$, summer mean $=27{ }^{\circ} \mathrm{C}$, autumn mean $=24.3$ $\left.{ }^{\circ} \mathrm{C}\right)$. Throughout the year, relative humidity presents high values over $65 \%$. The main wind direction is from northwest, while typically wind velocities range from $7-18 \mathrm{Km} / \mathrm{h}$. The average direction of solar irradiation is from the south. The microclimatic survey (this meant air, relative humidity and temperature, surface temperature) was carried out through NDT. An infrared camera and a portable thermo-hygrometer were used on each side and each drum of the south column, with an interval of about $10 \mathrm{~cm}$.

\subsection{Characterization of Materials and Decay}

For the characterization of materials and decay products, an infield diagnostic study was conducted. This study included the application of both NDT in-situ and analytical techniques in laboratory after sampling. The sampling process was performed under supervision of the Ephorate of Antiquities of Dodecanese, and included representative material areas based on results of the in-situ study for further analysis.

In particular, the NDT used, were: optical observation (including photography with a Nikon D80), digital microscopy with optical zoom x30, x50 x120, infrared thermography (FLIR B200), Schmidt hammer test (EN 12-504-2:2012) and finally, temperature and relative humidity measurements (FLIR MR77). The analytical techniques used on samples to assess the state of conservation were: Optical microscopy (Leica MZ6 coupled 
with digital camera DFC290) (digital analysis was performed), X-ray diffraction analysis (Bruker D8 Advance), Thermogravimetric analysis (Mettler Toledo 851), Scanning electron microscopy (JEOL JSM6380LV) coupled with Energy Dispersive X-Ray Analysis (Oxford Instruments INCAx-light), Mercury porosimetry (Macroscopes unit 120 corporation, Pascal 440 series Electron) (Normal 4/80 and Normal 27/88), Colorimetry (Dr Lange LMG268), water capillary absorption measurements (Normal 11/85) as well as total soluble salts measurements (Dossagio dei salt solubele, Normal 13/83).

\subsection{GIS: Design \& Implementation}

The integration of all the collected multidisciplinary, spatially interrelated information was performed in a GIS environment. The connection of the multitude of qualitative and quantitative data was executed based on their geospatial attributes.

The first step of creating the GIS platform was the logical design. The logical data model consisted of four levels. From general to more specific, these levels included: the monument, the parts of the monument incorporated in the study, the types of integrated data (type of documentation) and finally the categories of spatial entities corresponding to each type of recording.

The second step, was the classification of materials, decay and other spatial entities to create base maps. A detailed digitization of the façades (architectural features, outlines, materials, decay patterns and areas of application of NDT \& E), was achieved by importing the orthoimages into a $\mathrm{CAD}$ environment.

The third step was the organization of numeric and qualitative attributes available for some spatial entities. These included the mineralogical, microstructural, physicochemical, soluble-salts, chromatographic and environmental characteristics. In general, all the imported metric and qualitative information was attributed in a database.

The fourth step was the input of spatial data in ArcMap where the topology process was developed. This step was essential for the creation of spatial relationships among features of the same layer; that was for the construction of digital relationships which would be identifiable in the thematic maps and are related to connectivity, contiguity and adjacency (Delegou et al., 2013).

The final step was attributing the descriptive characteristics to the spatial entities/ features that constituted the thematic layers. Therefore, the topology was directly connected with the storing and (indirectly) the documentation of the corresponding attribute data which described the state of the monument. Ascribing the results of the diagnostic and environmental studies to the features of the GIS base map, during topology creation, led to the development of thematic maps of the building materials, decay and NDT \& E. The physical geodatabase included information such as the reports of the multidisciplinary studies and additional documentation data. Specifically, for the study of the materials, additional information included: IRT, FOM, OM and SEM images; EDX, SEM, TG and XRD diagrams.

\subsection{GIS: Visualization \& Management of Interrelated Data}

Building materials and decay patterns were classified according to spatial properties and physico-chemical characteristics, and were represented by a different layer and displayed by a different color. Thematic maps were produced not only for the materials and decay (Figures 11, 12), but also for the NDT \& E (Figure 13). Data retrieval was executed using relational operators to compare feature values associated with spatial data. Boolean operations were used to access and manipulate various entities and attributes (Figure 14).

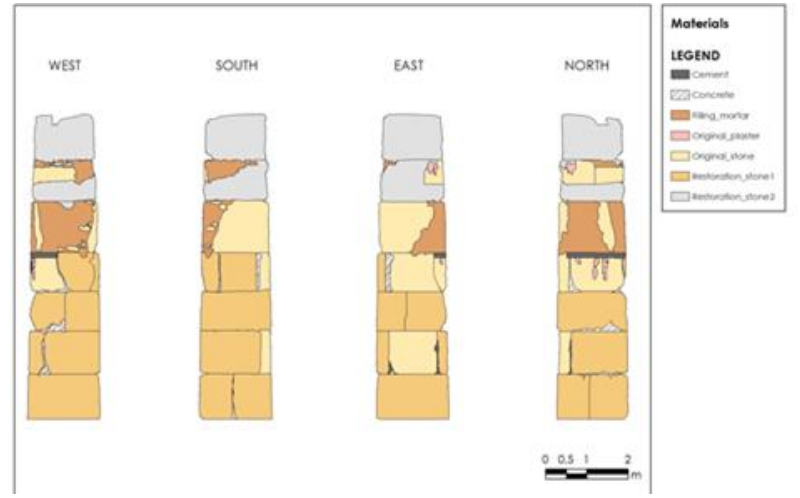

Figure 11: Thematic mapping of building materials

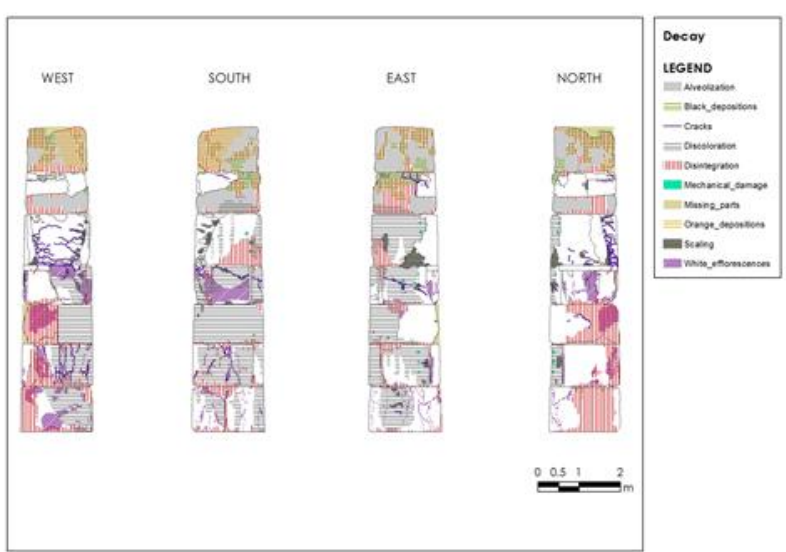

Figure 12: Thematic mapping of decay patterns

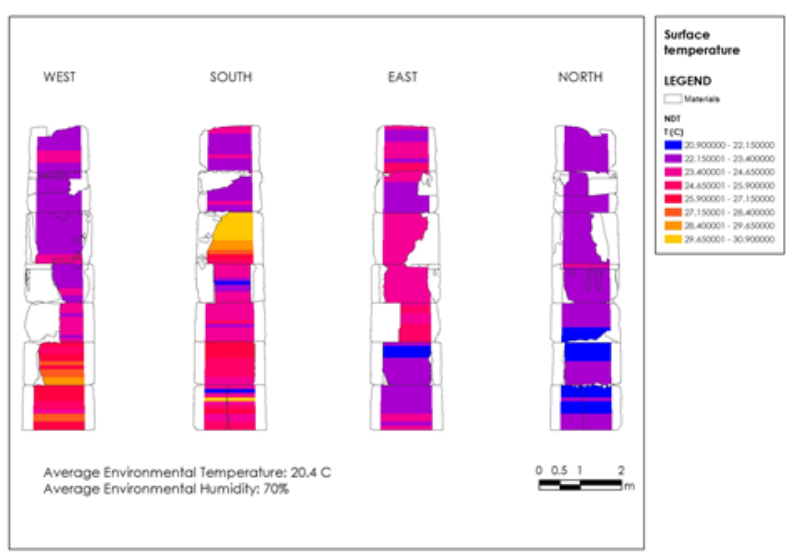

Figure 13: Thematic mapping of surface temperature

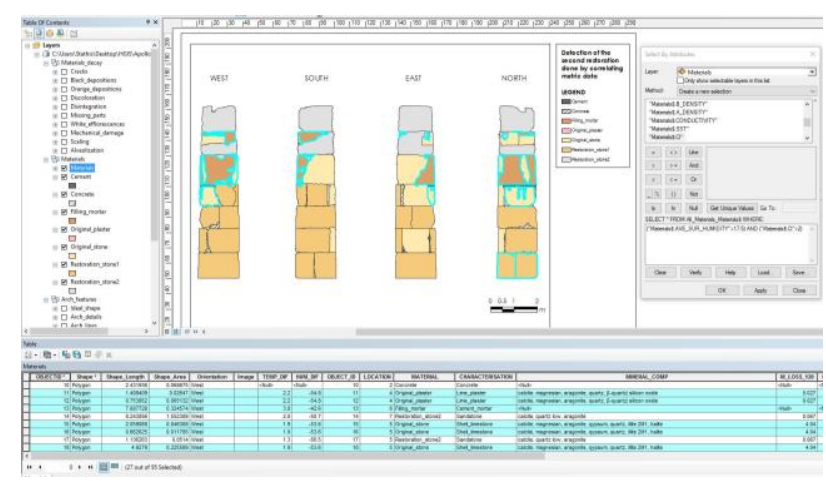

Figure 14: GIS analysis operations on the thematic map of building materials 


\subsection{GIS: Analysis and Results}

Detailed surface measurements and geoprocessing analysis were executed to identify the materials, assess previous interventions, identify the extent, causes and mechanisms of weathering and damage and interpret the relation of the climatic and microclimatic factors in conjunction with the characteristics of building materials. Several important results emerged.

Materials identification, initially made by visual observation, was verified by classification based on the characteristics attributed to each spatial entity. The building materials that predominate are the stones (biocalcarenite sandstone with poor consistency-microstructure). The original architectural surface (beige plaster) is retained at a very small percentage. Cement mortars have been used in previous interventions widely to complement the geometry, while concrete, used in the column core, becomes visible locally when there is a fragmentation of surrounding materials.

Regarding the impact of endogenous and exogenous factors, in general, the entire surface of the column is deteriorated; the decay is, to a large extent, particularly intense. Figure 15 demonstrated areas with intense (orange color) and mild (light green color) deterioration.

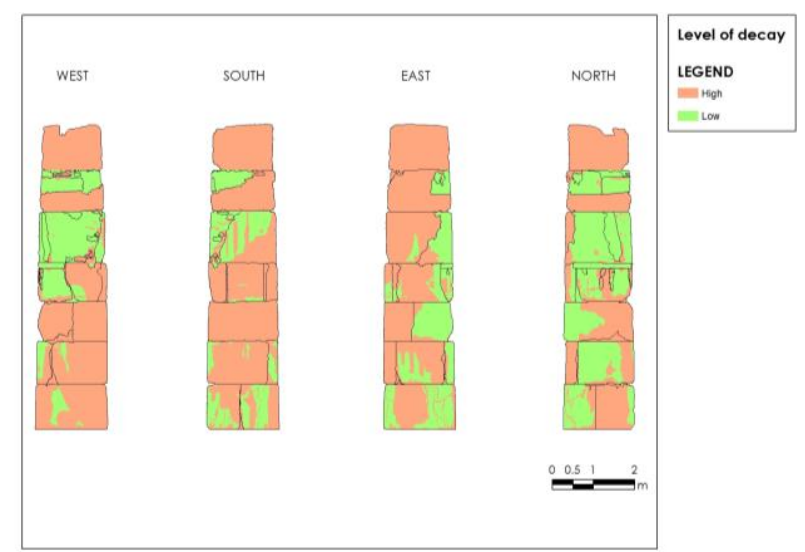

Figure 15: Thematic map of the level of decay (Orange: High level of decay; Light green: Low level of decay)

In the two upper drums, there are extensive depositions and alveolization. Due to the location, hue, surface morphology, and the permanently increased moisture, it is deducted that the depositions are of biological origin (moss and lichens). The rest of the surface is dominated by discolorations and disintegration. These types of decay are more common at the north and west, a pattern that is justified by the usual intense northwest winds that carry the seawater suspensions. On the surface of the column, white efflorescences and scaling appear to a lesser degree.

The distribution of thermal loads is justified by sun exposure (solar track). Considerable loads are concentrated on the south side of the column and result to cracks and scaling. Extremely high concentrations of soluble salts are located at the north, more exposed to the strong winds (directing from the sea) façade. Disintegration is largely caused by the effects of concrete on the neighboring calcareous materials.

\section{CONCLUDING REMARKS}

The process of the degradation of the building materials is determined by their mineralogical, physicochemical, mechanical characteristics, their environment and human interventions. Environmental conditions, location and orientation in the scale of a monument, play an important role in the development of decay products and consequently in the planning of rehabilitation interventions. Thus, the multidisciplinary methodology for documentation and diagnosis is very important. The collection of interdisciplinary data for complex and/or mixed historical structures is a complex process that should utilize all the available non-destructive documentation techniques. Using GIS, interdisciplinary data can be integrated and interrelated into a single system with common spatial reference. Thematic mapping of building materials provides important information on the construction and structural phases of the monument. Thematic mapping of the different types of decay assists the assessment of the real scale impact of endogenous and exogenous factors. In the case of the Temple of Pythian Apollo, the geospatial analysis based on the thematic layers and features attributed to the materials through the integrated documentation process (in the GIS) led to conclusions on the state of conservation of materials, on the impact of environmental factors and on the compatibility of the previous interventions on the monument.

Regarding a 3D representation and management of the data for the building materials and decay, such approach could not be easily implemented. An initial issue derives from the difficulty apprehending and more specifically measuring the third dimension, i.e. the depth. An approach of the depth could be tested through GPR and US testing or by other NDT \& E techniques, not applicable for the here mentioned case of study due to complex geometry and the multilayered information of construction materials. A second constraint refers to the inability of BIM to incorporate the required level of detail that would enable the analysis of interdisciplinary information regarding the materials and state of preservation. Thus, an integration of BIM and 3D GIS would be beneficial since both GIS and BIM application, including an external geodatabase, provide added value to the cultural heritage multidisciplinary field; but, this integrated approach. through the scope of materials is still under development. Currently, only the logic of a ' $2.5 \mathrm{D}$ ' approach has been explored mostly about historical castles, walls, facades or other flat geometries. Mostly those attempts utilize orthoimages or vertically captured IR images to provide a background for the simplistic visualization of the materials or construction phases. Although the representation of historic structures as multilayer objects simplistically is an approach that can be achieved, the attribution of the multidisciplinary qualitative and quantitative information to data structures and entities, still poses challenge.

\section{ACKNOWLEDGEMENTS}

The writers are grateful to the Ephorate of Antiquities of Dodecanese and especially to the Curator Maria Michailidou, to the Head of the Department of Prehistoric and Classical Archaeological Sites, Monuments, Archaeognostic Research and Museums Eleni Farmakidou and to Maria Pikoula, for their cooperation and their valuable contribution. The writers would also like to thank the archaeologist Dr. Elisa Fain for the concession of the drawings included in her doctoral dissertation: «Comportamento e durabilità delle "strutture miste"in area archeologica. Il Tempio di Apollo Pizio all' Acropoli di Rodi».

\section{REFERENCES}

Agrafiotis, P., Lampropoulos, K., Georgopoulos, A., and Moropoulou, A., 2017. 3D Modeling the invincible using ground penetrating radar, Int. Arch. Photogramm. Remote Sens. Spatial Inf. Sci., XLII-2/W3, pp.33-37.

Binda, L. and Saisi, A., 2001. State of the art of research on historic structures in Italy. Dept. of Structural Engineering, Politecnico of Milan, Italy.

Calisi, D., 2016. Photogrammetric survey and 3D modeling of the funerary urn depicting the Myth of Oenomaus, found inside the tomb of the Etruscan Family of Cacni in Perugia (III- 
I Century BC). In Proc. of the 8th International Conference on Archeology, Computer graphics, Cultural Heritage \& Innovation 'ARQUEOLÓGICA 2.0', in Valencia, Spain, pp.95-104.

Campos, M.B., Tommaselli, A.M., Ivánová, I., Billen, R., 2015. Data product specification proposal for architectural heritage documentation with photogrammetric techniques: A case study in Brazil. Remote Sensing, 7(10), pp.13337-13363.

Delegou, E.T., Kiranoudis, C., Sayas, J. and Moropoulou, A., 2012. Developing an integrated decision making system for the assessment of cleaning interventions on marble architectural surfaces. In 12th International Congress on Deterioration and Conservation of Stone, New York.

Delegou, E.T. Sandri, E. Marakakis, J. Sayas, J., Moropoulou, A., 2011. From building pathology to durability via GIS. In Proceedings of the12th International Conference on Durability of Building Materials and Components, Porto, pp.2185-2192.

Delegou, E.T., Tsilimantou, E., Oikonomopoulou, E., Sayas, J., Ioannidis, C. and Moropoulou, A., 2013. Mapping of building materials and consevation interventions using GIS: The case of Sarantapicho Acropolis and Erimokastro Acropolis in Rhodes. International Journal of Heritage in the Digital Era, 2(4), pp.631653.

De Reu, J., Plets, G., Verhoeven, G., De Smedt, P., Bats, M., Cherretté, B., De Maeyer, W., Deconynck, J., Herremans, D., Laloo, P. and Van Meirvenne, M., 2013. Towards a threedimensional cost-effective registration of the archaeological heritage. Journal of Archaeological Sc., 40(2), pp.1108-1121.

Fain, E., 2015. Comportamento e durabilità delle" strutture miste" in area archeologica. Il Tempio di Apollo Pizio all'Acropoli di Rodi. Doctoral dissertation. Politecnico di Milano, Italia (Relatore Prof.ssa C. Di Biase).

Genovese, R.A., 2005. Architectural, archaeologic and environmental restoration planning methodology: historic researches and techniques of survey aiming to conservation. In Proc. CIPA 5, pp.295-299.

Georgopoulos, A., 2016. 3D GEO: An alternative approach. ISPRS Annals of Photogrammetry, Remote Sensing and Spatial Information Sciences, IV-2/W1, pp.99-106.

Georgopoulos, A., Oikonomou, C., Adamopoulos, E. and Stathopoulou, E.K., 2016. Evaluating Unmanned Aerial Platforms for Cultural Heritage Large Scale Mapping. ISPRS International Archives of the Photogrammetry, Remote Sensing and Spatial Information Sciences, XLI-B5, pp.355-362.

Guarnieri, A., Remondino, F. and Vettore, A., 2006. Digital photogrammetry and TLS data fusion applied to Cultural Heritage 3D modeling. The International Archives of the Photogrammetry, Remote Sensing and Spatial Information Sciences, 36 (part 5).

IAEA, 2002. Guidebook on non-destructive testing of concrete structures, Industrial Applications and Chemistry Section, International Atomic Energy Agency, Vienna, Austria.

ICOMOS, 1964. International charter for the conservation and restoration of monuments and sites (The Venice Charter 1964). In 2nd International Congress of Architects \& Technicians of Historic Monuments.

Ioannidis, C. and Georgopoulos, A., 2007. Innovative techniques for the acquisition and processing of multisource data for the geometric documentation of monuments. International Journal of Architectural Computing, 5(2), pp.179-197.

Kioussi, A., Karoglou, M., Bakolas, A., Moropoulou, A., 2012. Integrated documentation protocols enabling decision making in cultural heritage protection. Progress in Cultural Heritage Preservation, pp.211-220.

Letellier, R., Schmid, W. and LeBlanc, F., 2007. Recording, documentation \& information management for the conservation of heritage places: Guiding principles, J. Paul Getty Trust.
Middendorf, B., Hughes, J.J., Callebaut, K., Baronio, G. and Papayianni, I., 2005a. Investigative methods for the characterisation of historic mortars-part 1: mineralogical characterisation. Materials and Structures, 38(8), pp.761-769.

Middendorf, B., Hughes, J.J., Callebaut, K., Baronio, G. and Papayianni, I., 2005b. Investigative methods for the characterisation of historic mortars-part 2: chemical characterisation. Materials and Structures, 38(8), pp.771-780.

Moropoulou, A., Chandakas, B., Togkalidou, T., Karoglou, M. Padouvas, E., 2003. A new methodology for quality control and monitoring of historic buildings: A tool for lifetime engineering. In Proceedings of 2nd International symposium, 'ILCDES' - Integrated Life-time Engineering of Buildings and Civil Infrastructures, Kuopio, pp.269-274.

Moropoulou, A., Delegou, E.T., Avdelidis, N.P., and Athanasiadou, A., 2005a. Integrated diagnostics using advanced in situ measuring technology. In Proceedings of the 10th international conference on durability of building materials and components, Lyon, pp.1116-1123.

Moropoulou, A., Delegou, E.T., Giannelos, J., Geraveli, M., Tsigkakou, K., 2005b. Data bases for the assessment, diagnosis and maintenance of buildings facades. In Proceedings of the 10th international conference on durability of building materials and components, Lyon.

Moropoulou, A., Koui, M., Tsiourva, T., Kourteli, C. and Papasotiriou, D., 1997. Macro-and micro-non-destructive tests for environmental impact assessment on architectural surfaces. In Materials Research Society Proceedings (462) pp. 343-349. Cambridge University Press.

Moropoulou, A., Labropoulos, K.C., Delegou, E.T., Karoglou, M. and Bakolas, A., 2013. Non-destructive techniques as a tool for the protection of built cultural heritage. Construction and Building Materials, 48, pp.1222-1239.

Nasser, N., 2003. Planning for urban heritage places: reconciling conservation, tourism, and sustainable development. CPL bibliography, 17(4), pp.467-479.

Nocerino, E., Menna, F., Remondino, F., 2014. Accuracy of typical photogrammetric networks in cultural heritage 3D modeling projects. ISPRS Archives, 40(5), pp. 465-472.

Pereira, H.N., 2007. Contemporary trends in conservation: Culturalization, significance \& sustainability. City \& Time, 3(2), pp.15-25.

Pierrot-Deseilligny, M., De Luca, L., Remondino, F., 2011. Automated image-based procedures for accurate artifacts 3D modeling and orthoimage generation. Geoinformatics FCE CTU, 6, pp.291-299.

Salonia, P. and Negri, A., 2003. Historical buildings and their decay: Data recording, analysing and transferring in an ITC environment. ISPRS Archives, 34(5/W12), pp.302-306.

Tsilimantou, E., 2018. Integrated data management environment, regarding materials characterization and decay diagnosis, using Geographic Information Systems, in the scale of Historical Buildings and Monuments. PhD Thesis, National Technical University of Athens, Greece (supervisor Prof. A. Moropoulou) (under development).

UNESCO, 1981. Advice and suggestions or the furtherance of optimum practice in architectural photogrammetry surveys. Prepared by CIPA of the ICOMOS.

Van Genechten, B., 2008. Theory \& practice on Terrestrial Laser Scanning: Training material based on practical applications.

Yilmaz, H.M., Yakar, M., Gulec, S.A. and Dulgerler, O.N., 2007. Importance of digital close-range photogrammetry in documentation of cultural heritage. Journal of Cultural Heritage, 8(4), pp.428-433. 